\title{
ARTICLE OPEN \\ Pulmonary rehabilitation and sleep quality: a before and after controlled study of patients with chronic obstructive pulmonary disease
}

\author{
Lucy M McDonnell ${ }^{1}$, Lauren Hogg ${ }^{2}$, Lynn McDonnell ${ }^{2}$ and Patrick White ${ }^{1}$
}

BACKGROUND: Poor sleep quality is common in chronic obstructive pulmonary disease (COPD). It is associated with poor quality of life. Pulmonary rehabilitation (PR) improves quality of life, exercise capacity, and anxiety and depression. Its effect on sleep quality is uncertain.

AIM: To determine whether PR improves sleep quality in COPD.

METHODS: A prospective controlled 'before and after' study of sleep quality in COPD patients attending a community PR programme was conducted. Sleep quality was measured using the Pittsburgh Sleep Quality Index (PSQI). Lung function, diseasespecific quality of life (COPD assessment test-CAT), exercise capacity (incremental shuttle walk test-ISWT), and anxiety and depression (Hospital Anxiety and Depression Scale-HADS) were measured. Change in sleep quality was compared with a COPD control group.

RESULTS: Twenty-eight participants completed PR. The control group comprised 24 patients. Prevalence of poor sleep quality (PSQI $\geqslant 5$ ) was $78 \%$. There were no differences between observation and control groups in sleep quality, age or severity. Quality of life was strongly correlated with quality of sleep $(r=0.64, P<0.001)$. PR improved the quality of life (CAT change 3.0; $95 \%$ $\mathrm{Cl}, 0.7-5.3$ ), exercise capacity (ISWT change (metres) $81.0 ; 15.3-146.6$ ), anxiety (HADS score $\geqslant 8$ : change 2.33 ; $0.45-4.22$ ), and depression (HADS score $\geqslant 8$ : change $2.90 ; 1.92-3.88$ ). PR did not improve sleep quality (PSQI mean change $0.79 ;-0.35$ to 1.93 ). CONCLUSIONS: PR did not improve sleep quality in COPD despite improving quality of life, exercise capacity, anxiety and depression. New strategies, independent of PR, are required to improve sleep quality in COPD.

npj Primary Care Respiratory Medicine (2014) 24, 14028; doi:10.1038/npjpcrm.2014.28; published online 10 July 2014

\section{INTRODUCTION}

Sleep-related disturbances and insomnia have been shown to be higher in chronic obstructive pulmonary disease (COPD) sufferers than in the general population, with between 50 and $70 \%$ of patients reporting difficulty in initiating or maintaining sleep, or poor sleep quality. ${ }^{1,2}$ Disturbed sleep has been found to be associated with more severe disease, frequent exacerbations and increased mortality in COPD. ${ }^{3}$ Sleep quality is a good predictor of quality of life in patients with stable COPD. ${ }^{2,4}$

The underlying mechanism for poor sleep quality in COPD is under debate. Sleep may be disturbed by cough or dyspnoea. ${ }^{3}$ In addition, nocturnal oxygen desaturation (NOD) in patients with COPD has been investigated as a cause of nocturnal arousals, ${ }^{5}$ but may be less of a stimulant than hypercapnia. ${ }^{6}$ NOD probably occurs due to a variety of mechanisms, including more pronounced alveolar hypoventilation, particularly during REM sleep, ${ }^{7}$ over-reliance on respiratory musculature ${ }^{8}$ and ventilation/ perfusion mismatch. ${ }^{5,7}$ Daytime hypoxaemia has been shown to be independently associated with impaired sleep efficiency. ${ }^{9}$ However, NOD can occur in COPD patients with mild or absent daytime hypoxaemia. ${ }^{10-12}$

The relationship between NOD and sleep quality is unclear. ${ }^{13}$ Lewis et al. ${ }^{14}$ found no significant difference in self-reported sleep quality between nocturnal desaturators and non-desaturators in 59 patients with resting saturations of $<95 \%$ recruited from an outpatient COPD clinic. Improvements in nocturnal hypoxaemia have been seen in patients taking salmeterol ${ }^{15}$ and tiotropium, ${ }^{16}$ without consequent improvement in polysomnography or subjective sleep quality. Recently Nunes et al. ${ }^{17}$ showed that melatonin may have potential for improving sleep quality in COPD.

There has been little research into non-pharmacological methods to improve sleep quality in patients with COPD. In an uncontrolled observational study in the United States, Soler et al. ${ }^{18}$ showed that pulmonary rehabilitation (PR) was associated with a statistically significant improvement in sleep quality although the improvement in Pittsburgh Sleep Quality Index (PSQI) score of 1.1 was well short of the minimal clinically important difference of 3.0. ${ }^{19}$ The potential for PR, an important aspect in the management of $C O P D,{ }^{20}$ to improve sleep quality remains uncertain.

The hypothesis that PR may improve sleep quality is based on the observation that PR has been shown to improve quality of life and exercise capacity, ${ }^{21}$ and anxiety and depression. ${ }^{22}$ Anxiety and depression have been specifically associated with poor sleep. ${ }^{23}$ The prevalences of anxiety and depression are higher in patients with COPD than in the general population. ${ }^{24,25}$ A recent systematic review of the effects of exercise training on sleep quality in middle-aged to older adults with sleep problems found that

\footnotetext{
'Department of Primary Care and Public Health Sciences, King's College London, King's Health Partners, London, UK and 'Department of Physiotherapy, Guy's and St Thomas' NHS Foundation Trust, St Thomas' Hospital, London, UK.

Correspondence: P White (patrick.white@kcl.ac.uk)

Received 14 January 2014; revised 3 May 2014; accepted 26 May 2014
} 
participation in an exercise programme had moderately positive effects on sleep. ${ }^{26}$

Our research aimed to determine whether PR improved sleep quality in patients with COPD.

\section{MATERIALS AND METHODS}

\section{Study design and setting}

We carried out an observational 'before and after' study of patients with COPD attending an 8-week community PR programme. We compared selfreported sleep quality before and after attendance at hospital or community-based PR using the PSQI. ${ }^{27} \mathrm{~A}$ control group of patients with COPD was simultaneously recruited from a general practice in the same community to ensure that changes in sleep quality in the observation group after completion of PR could be compared to changes in the control group over a comparable period. Research ethical approval was obtained (NRES Committee London-Central reference 11/LO/1156).

\section{Participants}

The study group under observation was recruited from five hospital and community sites in South East London. All patients referred to PR (community and hospital referrals) from November 2011 until June 2012 were invited to participate in the research at their initial assessment Eligibility criteria for the study included a diagnosis of COPD confirmed by spirometry (forced expiratory volume in $1 \mathrm{~s}\left(\mathrm{FEV}_{1}\right) /$ forced vital capacity ratio (FVC) <0.7) according to GOLD criteria ${ }^{28}$ and suitability for participation in PR. Consent to participate in the study was implied by completion of the first sleep questionnaire. Participants who attended PR at least once a week for 8 weeks were invited to complete a second questionnaire.

The control group was recruited from a general practice in the same area. Patients on the practice COPD register suitable for referral to PR (criteria identical to the observation group) were invited by letter to participate in the study, and supplied with a copy of the PSQI. Consent to participate in the study was implied by completion of the first questionnaire. A second questionnaire was sent $\sim 8$ weeks later. Reminder letters were sent to patients who did not return the second PSQI.

\section{Instruments}

Sleep quality was measured in the observation and control groups using the PSQI, a self-rated subjective questionnaire comprising 19 individual questions that generate seven 'component' scores (sleep quality, sleep latency, sleep duration, habitual sleep efficiency, sleep disturbances, use of sleeping medication and daytime dysfunction). ${ }^{27}$ Each component score is marked from 0 to 3 , with a maximum total score of 21 and a minimum score of 0 . The sum of the component scores yields a global PSQI score. A global score $<5$ indicates 'good' overall sleep quality, whereas a score $\geqslant 5$ indicates 'poor' sleep quality with a diagnostic sensitivity and specificity of $89.6 \%$ and $86.5 \%$, respectively. ${ }^{27}$ In comparison with other tools to measure sleep, the PSQI has undergone extensive psychometric evaluation. ${ }^{29}$ It has been shown to have high test-retest reliability ${ }^{30}$ and construct validity ${ }^{31}$ and has a reported minimal clinically important difference of $3 .^{19}$

Respiratory specific quality of life was measured using the COPD assessment test (CAT), ${ }^{32}$ exercise capacity was measured using the incremental shuttle walk test (ISWT), ${ }^{33}$ and anxiety and depression were measured using the Hospital Anxiety and Depression Scale (HADS). ${ }^{34}$

\section{Data analysis}

Sample size calculation was based on average PSQ scores in previous research with similar patients, 4,35 and a minimal clinically important difference of 3 between before and after measurements. ${ }^{19}$ An expected correlation of $r=0.8$ between before and after PSQI measurements was used (compared to published values of 0.85 ) as the interval between before and after measurements in this study was slightly longer (PR course took place over 8 weeks). ${ }^{27}$ Twenty-five patients with complete data were required in the intervention and control groups to give $90 \%$ power to detect a difference at the $5 \%$ significance level. To allow for drop-outs and losses to follow-up of $40 \%$, at least 42 patients were approached in each group.

We analysed the data using SPSS $\vee 20$ (IBM, New York, NY, USA). The primary outcome measure was the change in individual PSQI scores in the observation group, before and after $\mathrm{PR}$, compared with change in the control group. Secondary outcome measures were changes in HADS, CAT and exercise test scores in the observation group. We used the pairedsamples Student $t$-test to compare means before and after, and the independent-samples Student $t$-test to compare differences between the two groups at baseline. Pearson's product moment co-efficient $(r)$ was used to analyse association between changes in HADS, PSQI and CAT scores in the observation group.

\section{RESULTS}

\section{Demographics}

Sixty-one eligible patients were recruited for the observation arm of the study, of whom 31 completed at least eight sessions of PR. Of these, 28 completed the first and second PSQI and were included in the final analysis. Recruited patients who completed PR or who were excluded or dropped out from the observation arm of the study are shown in Figure 1. The drop-out rate after the first assessment was $49 \%$. Forty-two patients were invited to participate in the control group, of whom 24 returned the first and second PSQI.

\section{Prevalence of poor sleep quality}

The prevalence of poor sleep quality (PSQI $\geqslant 5$ ) in both the observation and control groups was $75 \%$, with no statistically significant difference between them with respect to initial PSQ scores $(t=-0.735, P=0.466)$. There was no difference between the baseline PSQI scores in the observation group and the 'drops-out/ excluded participants' group ( $t=-1.836, P=0.71$ ). There were no significant differences between the observation group and control group with respect to age (independent-samples $t$-test $t=1.776$ $P=0.082)$ or disease severity (FEV $\%$ predicted) $(t=0.495$ $P=0.623$ ) (Table 1).

Correlations between PSQI scores and anxiety, depression and health-related quality of life at baseline

The correlations between self-reported sleep quality, anxiety, depression and disease-specific health status using data compiled

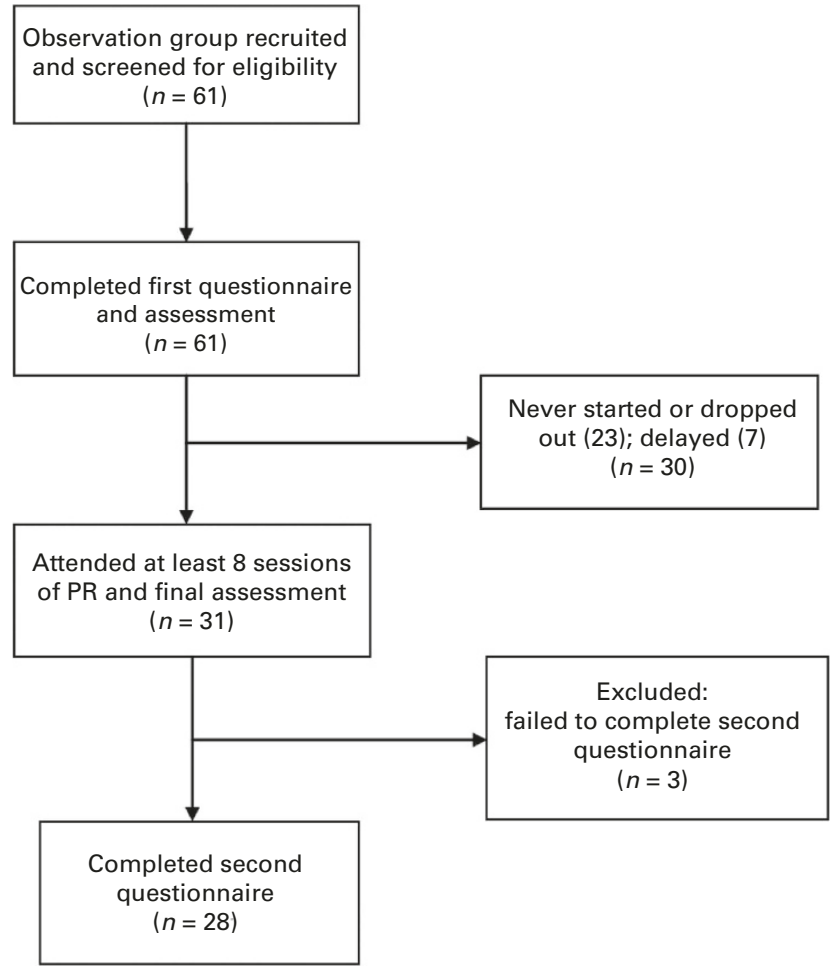

Figure 1. Recruitment and participation of patients in the observation group. 
from the 61 patients who entered the study are shown in Table 2. Poor sleep quality was significantly correlated with high anxiety scores, high depression scores and worse disease-specific health status $(P \leqslant 0.02)$. Global PSQI was not associated with disease severity as measured by $\mathrm{FEV}_{1} \%$ predicted ( $r=-0.025, P=0.864$ ). Global PSQI score was negatively associated with age $(r=-0.26$, $P=0.01$ ).

The effect of PR on sleep quality

There were no significant differences between before and after scores in the observation and control groups with regard to sleep quality (see Table 3).

When the global PSQI score was broken down into its seven components there were no clinically or statistically significant differences between the pre and post scores in any component.

The effect of PR on depression, anxiety and disease-specific health status

The effect of PR on disease-specific health status (CAT), depression and anxiety (HADS) and exercise capacity (ISWT) is shown in Table 4. There were statistically significant improvements in the observation group pre and post scores with regard to overall disease-specific health status, overall distance walked, and anxiety and depression in those with scores $\geqslant 8$ at baseline. The average overall distance walked of $81 \mathrm{~m}$ exceeded the MCID of $47.5 \mathrm{~m} .{ }^{36}$

\section{DISCUSSION}

Main findings

PR had no effect on sleep quality in this controlled study of the effect of PR on sleep in patients with COPD. Most COPD patients undergoing PR had poor sleep quality. The PR treatment was effective in improving quality of life and exercise capacity and in improving depression and anxiety in those with at least mild symptoms, but these effects were not associated with improvements in sleep.

This study was designed to test the concept that PR might improve sleep in participants who received routine referrals to PR. Their characteristics, including the drop-out rate, reflected those of COPD referrals previously reported in this locality and in other studies. ${ }^{37,38}$ The prevalence and severity of poor sleep quality was similar to that already reported in COPD., ${ }^{2,4}$ The extent of improvement in exercise capacity and quality of life, and in mood in those with symptoms of depression or anxiety, showed that the PR treatment was at least as effective as expected. There was no

Table 1. Demographics of observation group patients who completed PR, control group and observation group drop-out/excluded participants

\begin{tabular}{llcr}
\hline & $\begin{array}{c}\text { Observation group } \\
\text { completed }(\mathrm{n}=28)\end{array}$ & Control group $(\mathrm{n}=24)$ & $\begin{array}{c}\text { Observation group } \\
\text { drop-out/excluded }(\mathrm{n}=33)\end{array}$ \\
\hline Age (years) (s.d.) & $68.1(11.3)$ & $73.1(8.5)$ & $62.67(11.1)$ \\
Gender & $13(46 \%)$ male & $11(46 \%)$ male & $15(45 \%) \mathrm{male}$ \\
FEV 1 \% predicted (s.d.) & $55 \%(19.2)(n=27)$ & $57 \%(15.5)(n=23)$ & $49 \%(16.3)(n=30)$ \\
FEV $/$ FVC ratio (s.d.) & $0.49(12.1)$ & $0.55(11.7)$ & $0.53(12.0)$ \\
Initial PSQI score (s.d.) & $8.04(4.6)$ & $9.04(5.3)$ & $10.21(4.6)$ \\
\hline
\end{tabular}

Abbreviations: $\mathrm{FEV}_{1}$, forced expiratory volume in $1 \mathrm{~s} ; \mathrm{FVC}=$ forced vital capacity; $n$, number in group; PSQI, Pittsburgh Sleep Quality Index; s.d., standard deviation.

Table 2. Correlation between sleep quality, anxiety, depression and health-related quality of life at baseline

\begin{tabular}{|c|c|c|c|c|c|}
\hline r-value & PSQI & CAT & HADS-A & HADS-D & ISWT \\
\hline PSQI (n) & $1(61)$ & $0.523^{\mathrm{a}}(60)$ & $0.461^{\mathrm{a}}(57)$ & $0.410^{\mathrm{a}}(57)$ & $-0.161(48)$ \\
\hline CAT $(n)$ & $0.523^{\mathrm{a}}(60)$ & $1(60)$ & $0.429^{\mathrm{a}}(57)$ & $0.300^{\mathrm{b}}(57)$ & $-0.401^{\mathrm{a}}(48)$ \\
\hline HAD-A (n) & $0.461^{\text {a }}(57)$ & $0.429^{\mathrm{a}}(60)$ & 1 (57) & $0.609^{\mathrm{a}}(57)$ & $-0.128(48)$ \\
\hline HAD-D $(n)$ & $0.410^{\mathrm{a}}(57)$ & $0.300^{\mathrm{b}}(57)$ & $0.609^{\mathrm{a}}(57)$ & 1 (57) & $-0.346^{\mathrm{b}}(48)$ \\
\hline ISWT $(n)$ & -0.161 & $-0.401^{\mathrm{a}}(48)$ & $-0.128(48)$ & $-0.346^{\mathrm{b}}(48)$ & $1(48)$ \\
\hline
\end{tabular}

Abbreviations: CAT = COPD assessment test; HADS-A, Hospital Anxiety and Depression Scale-anxiety score; HADS-D, Hospital Anxiety and Depression Scale-depression score; ISWT, incremental shuttle walk test; $n$, number in group; PSQI = Pittsburgh Sleep Quality Index at baseline.

${ }^{a}$ Correlation is significant at the 0.01 level (2-tailed).

${ }^{\mathrm{b}}$ Correlation is significant at the 0.05 level (2-tailed).

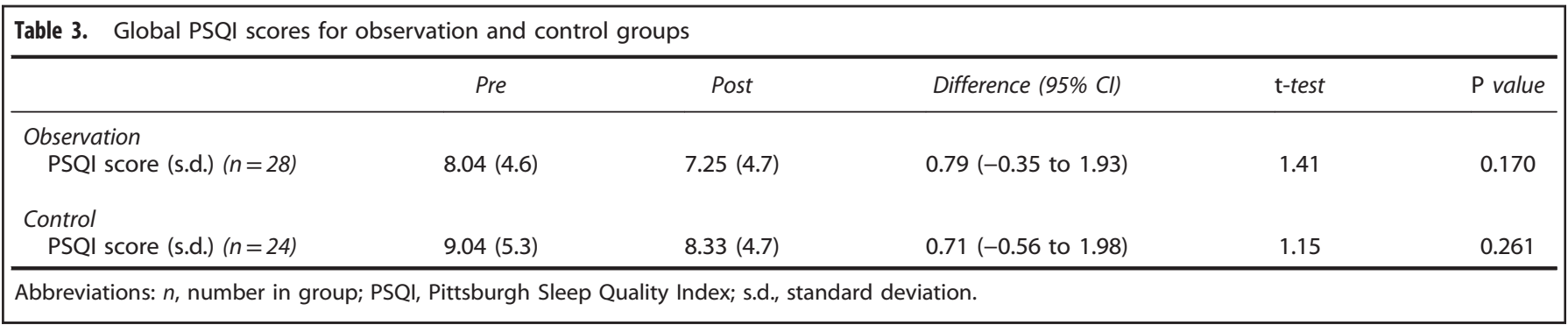


Table 4. The effect of PR on disease-specific health status (CAT score), anxiety (HADS), depression (HADS) and exercise capacity (ISWT) (observation group)

\begin{tabular}{|c|c|c|c|c|c|}
\hline & Pre & Post & Difference & $t$-test & $\mathrm{P}$ value \\
\hline CAT score (s.d.) $(n=27)$ & $19.30(7.6)$ & $16.30(9.1)$ & $3.00(0.70-5.30)$ & 2.68 & 0.013 \\
\hline HADS-anxiety score (s.d.) $(n=27)$ & $7.52(5.1)$ & $6.63(4.9)$ & $0.89(-0.36$ to 2.14$)$ & 1.46 & 0.16 \\
\hline Anxiety score $\geqslant 8$ (s.d.) $(n=12)$ & 12.25 (3.4) & $9.92(4.8)$ & $2.33(0.45-4.22)$ & 2.73 & 0.020 \\
\hline HADS-depression score (s.d.) $(n=27)$ & $5.96(4.8)$ & $4.96(3.9)$ & $1.00(-0.16$ to 2.16$)$ & 1.77 & 0.09 \\
\hline Depression score $\geqslant 8$ (s.d.) $(n=10)$ & $11.00(3.8)$ & $8.10(3.8)$ & $2.90(1.92-3.88)$ & 6.69 & $<0.0001$ \\
\hline ISWT (m) (s.d.) $(n=20)$ & $295.50(126.0)$ & 376.50 (189.6) & $81.0(15.3-146.6)$ & 2.54 & 0.018 \\
\hline
\end{tabular}

Abbreviations: CAT, COPD assessment test; HADS, Hospital Anxiety and Depression Scale; ISWT, incremental shuttle walk test; PR, pulmonary rehabilitation; s.d., standard deviation.

reason to suspect that the lack of effect on sleep quality was due to ineffectiveness of PR

The strong correlation between sleep quality, health status and depression scores on entry to the study raised the expectation that sleep might improve if quality of life or mood also improved in this group. The absence of improvement in sleep quality even when health status and mood improved was notable. While deterioration in sleep quality in these patients may have occurred in association with or even as a result of deterioration in quality of life and mood, its recovery does not appear to have the same relationship. There was no evidence that poor sleep in COPD was related to exercise capacity.

\section{Strengths and limitations of the study}

The PSQI is a well-validated, reliable and repeatable tool for the assessment of sleep quality. We acknowledge that polysomnography is the gold standard. In this study we had the additional reassurance of the assessment of sleep quality measured in a control group of comparable COPD patients from the same community. The observation and control groups were not matched, but the quality of sleep of patients in the control group was similar to that in the observation group on entry to the study. We recruited 24 patients into the control group (required sample size 25), but this did not affect the interpretation of the results as there were no differences between the two groups at baseline or in the change in sleep quality over the weeks studied. The control group response rate of $57 \%$ was above that observed in other similar COPD studies. ${ }^{39,40}$

Interpretation of findings in relation to previously published work The change in PSQI scores we found before and after PR was of a similar magnitude to that recently reported in an observational study by Soler et al. ${ }^{18}$ Soler et al. reported a change in sleep quality following PR in 46 patients with COPD. The authors reported a difference in PSQI scores of $1.1(6.6-5.5)$, similar to the reduction of 0.79 (8.04-7.25) in our study. These minimal changes observed are well short of the MCID for the PSQI of 3. We also found a reduction in PSQI scores of a similar magnitude (0.71) in the control group. Soler et al. did not recruit a control group.

We were able to demonstrate that PR was effective in our study by reporting an improvement in the walking distance of $81 \mathrm{~m}$, surpassing the MCID for the ISWT of $47.5 \mathrm{~m}$. The PR intervention in the study by Soler et al. resulted in an improvement in the 6-min walking distance of approximately $45 \mathrm{~m}$, less than the MCID of $54 \mathrm{~m}$. This suggests that the rehabilitation programme in that study was not achieving the standard improvement in walking distance and brings into question the authors' assertion that changes in sleep quality may have been related to physical activity. Our study shows that despite clinically and statistically significant improvement in walking distance, we observed no concurrent improvement in sleep quality.

With regard to how changes in mood affect sleep, Hynninen et $a l^{41}$ found that although a course of CBT in COPD patients with known anxiety or depression improved both anxiety and depression, subjective sleep quality as measured by the PSQI did not improve. In our study the close relationship between poor sleep quality and anxiety and depression at baseline was also not reflected in the recovery of sleep with the resolution of anxiety and depression.

Implications for future research, policy and practice

The underlying physiological causes of poor sleep in COPD have been well researched, but our understanding of why patients with COPD continue to sleep poorly is limited. A variety of factors are likely to be interacting. Worse quality of life and psychological well-being together with the physiological disruption of daytime and nocturnal hypoxaemia may lead to a disruption in sleep pattern. The chronic insult to sleep architecture, or the onset of a specific symptom that disrupts sleep in an individual, may lead to a change in sleep behaviour that cannot be overcome by simply removing the cause. To address the change in behaviour, which has now become chronic, a systematic approach to poor sleep quality may be required. Cognitive behavioural therapy for insomnia, which includes basic sleep hygiene, has shown promising results in patients with COPD but requires more study. ${ }^{42}$

\section{Conclusions}

Poor sleep is a common outcome of COPD, which does not improve with the improvements in quality of life or with the relief of psychological distress that is achieved by participation in PR. It is therefore likely that restoration of the pattern of sleep in COPD will require more specific interventions that aim to restore sleep behaviour without reference to the original cause.

\section{ACKNOWLEDGEMENTS}

We are grateful to Tony de Boeck, at the Pulmonary Rehabilitation team, Dulwich Hospital, for collating the data and updating the spreadsheets, and to Dr Rachel Garrod and the other physiotherapists in the Pulmonary Rehabilitation teams at Guys and St Thomas' NHS Trust and Kings College Hospital NHS Trust for their help with recruiting patients and administering the questionnaires.

\section{CONTRIBUTIONS}

LMM conceived the idea, developed the research protocol, analysed the data and wrote the paper. LM and LH recruited the observation group, collected the data and reviewed earlier drafts of the paper. PW reviewed the research protocol, recruited the control group, analysed the data and wrote the paper in conjunction with LMM. PW is the guarantor. 


\section{COMPETING INTERESTS}

The authors declare no conflict of interest.

\section{FUNDING}

LMM undertook this work as part of a Masters degree funded by the Medical Research Council Alice Cory Early Research Training fellowship scheme (Ref C0342).

\section{REFERENCES}

1 Klink M, Quan SF. Prevalence of reported sleep disturbances in a general adult population and their relationship to obstructive airways diseases. Chest 1987; 91: 540-546.

2 Nunes DM, Mota RM, de Pontes Neto OL, Pereira ED, de Bruin VM, de Bruin PF. Impaired sleep reduces quality of life in chronic obstructive pulmonary disease. Lung 2009; 187: 159-163.

3 Omachi TA, Blanc PD, Claman DM, Chen H, Yelin EH, Julian L et al. Disturbed sleep among COPD patients is longitudinally associated with mortality and adverse COPD outcomes. Sleep Med 2012; 13: 476-483.

4 Scharf SM, Maimon N, Simon-Tuval T, Bernhard-Scharf BJ, Reuveni H, Tarasiuk A Sleep quality predicts quality of life in chronic obstructive pulmonary disease. Int $J$ Chron Obstruct Pulmon Dis 2010; 6: 1-12.

5 Cormick W, Olson LG, Hensley MJ, Saunders NA. Nocturnal hypoxaemia and quality of sleep in patients with chronic obstructive lung disease. Thorax 1986; 41: 846-854.

6 Hedemark LL, Kronenberg RS. Ventilatory and heart rate responses to hypoxia and hypercapnia during sleep in adults. J Appl Physiol Respir Environ Exerc Physiol 1982; 53: 307-312.

7 Douglas NJ, Calverley PM, Leggett RJ, Brash HM, Flenley DC, Brezinova V. Transient hypoxaemia during sleep in chronic bronchitis and emphysema. Lancet 1979; 1 (8106): 1-4.

8 Johnson MW, Remmers JE. Accessory muscle activity during sleep in chronic obstructive pulmonary disease. J Appl Physiol 1984; 57: 1011-1017.

9 McSharry DG, Ryan S, Calverley P, Edwards JC, McNicholas WT. Sleep quality in chronic obstructive pulmonary disease. Respirology 2012; 17: 1119-1124.

10 Fletcher EC, Miller J, Divine GW, Fletcher JG, Miller T. Nocturnal oxyhemoglobin desaturation in COPD patients with arterial oxygen tensions above $60 \mathrm{~mm} \mathrm{Hg}$. Chest 1987; 92: 604-608.

11 Levi-Valensi P, Weitzenblum E, Rida Z, Aubry P, Braghiroli A, Donner C et al. Sleeprelated oxygen desaturation and daytime pulmonary haemodynamics in COPD patients. Eur Respir J 1992; 5: 301-307.

12 Vos PJ, Folgering HT, van Herwaarden CL. Predictors for nocturnal hypoxaemia (mean $\mathrm{SaO} 2<90 \%$ ) in normoxic and mildly hypoxic patients with COPD. Eur Respir J 1995; 8: 74-77.

13 McNicholas WT, Verbraecken J, Marin JM. Sleep disorders in COPD: the forgotten dimension. Eur Respir Rev 2013; 22: 365-375.

14 Lewis CA, Fergusson W, Eaton T, Zeng I, Kolbe J. Isolated nocturnal desaturation in COPD: prevalence and impact on quality of life and sleep. Thorax 2009; 64: 133-138.

15 Ryan S, Doherty LS, Rock C, Nolan GM, McNicholas WT. Effects of salmeterol on sleeping oxygen saturation in chronic obstructive pulmonary disease. Respiration 2010; 79: 475-481.

16 McNicholas WT, Calverley PM, Lee A, Edwards JC. Long-acting inhaled anticholinergic therapy improves sleeping oxygen saturation in COPD. Eur Respir $J$ 2004; 23: 825-831.

17 Nunes DM, Mota RM, Machado MO, Pereira ED, Bruin VM, Bruin PF. Effect of melatonin administration on subjective sleep quality in chronic obstructive pulmonary disease. Braz J Med Biol Res 2008; 41: 926-931.

18 Soler X, Diaz-Piedra C, Ries AL. Pulmonary rehabilitation improves sleep quality in chronic lung disease. COPD 2013; 10: 156-163.

19 Hughes CM, McCullough CA, Bradbury I, Boyde C, Hume D, Yuan J et al. Acupuncture and reflexology for insomnia: a feasibility study. Acupunct Med 2009; 27: 163-168.

20 Seymour JM, Moore L, Jolley CJ, Ward K, Creasey J, Steier JS et al. Outpatient pulmonary rehabilitation following acute exacerbations of COPD. Thorax 2010; 65 (5): 423-428.

21 Lacasse Y, Martin S, Lasserson TJ, Goldstein RS. Meta-analysis of respiratory rehabilitation in chronic obstructive pulmonary disease. A Cochrane systematic review. Eura Medicophys 2007; 43: 475-485.
22 Paz-Diaz H, Montes de Oca M, Lopez JM, Celli BR. Pulmonary rehabilitation improves depression, anxiety, dyspnea and health status in patients with COPD. Am J Phys Med Rehabil 2007; 86: 30-36.

23 Mayers AG, Grabau EA, Campbell C, Baldwin DS. Subjective sleep, depression and anxiety: inter-relationships in a non-clinical sample. Hum Psychopharmacol 2009; 24: 495-501.

24 Janssen DJ, Spruit MA, Leue C, Gijsen C, Hameleers H, Schols JM et al. Symptoms of anxiety and depression in COPD patients entering pulmonary rehabilitation. Chron Respir Dis 2010; 7: 147-157.

25 Zhang MW, Ho RC, Cheung MW, Fu E, Mak A. Prevalence of depressive symptoms in patients with chronic obstructive pulmonary disease: a systematic review, meta-analysis and meta-regression. Gen Hosp Psychiatry 2011; 33: 217-223.

26 Yang PY, Ho KH, Chen HC, Chien MY. Exercise training improves sleep quality in middle-aged and older adults with sleep problems: a systematic review. J Physiother 2012; 58: 157-163.

27 Buysse DJ, Reynolds CF 3rd, Monk TH, Berman SR, Kupfer DJ. The Pittsburgh Sleep Quality Index: a new instrument for psychiatric practice and research. Psychiatry Res 1989; 28: 193-213.

28 GOLD. Global Strategy for the diagnosis, management and prevention of chronic obstructive lung disease 2011, Available from http://www.goldcopd.org (accessed on 7 April 2012).

29 Devine EB, Hakim Z, Green J. A systematic review of patient-reported outcome instruments measuring sleep dysfunction in adults. Pharmacoeconomics 2005; 23: 889-912.

30 Backhaus J, Junghanns K, Broocks A, Riemann D, Hohagen F. Test-retest reliability and validity of the Pittsburgh Sleep Quality Index in primary insomnia. J Psychosom Res 2002; 53: 737-740.

31 Carpenter JS, Andrykowski MA. Psychometric evaluation of the Pittsburgh Sleep Quality Index. J Psychosom Res 1998; 45: 5-13.

32 Jones PW, Harding G, Berry P, Wiklund I, Chen WH, Kline Leidy N. Development and first validation of the COPD Assessment Test. Eur Respir J 2009; 34: 648-654.

33 Singh SJ, Morgan MD, Scott S, Walters D, Hardman AE. Development of a shuttle walking test of disability in patients with chronic airways obstruction. Thorax 1992; 47: 1019-1024.

34 Zigmond AS, Snaith RP. The hospital anxiety and depression scale. Acta Psychiatr Scand 1983; 67: 361-370.

35 Shackell BS, Jones RC, Harding G, Pearse S, Campbell J. 'Am I going to see the next morning?' A qualitative study of patients' perspectives of sleep in COPD. Prim Care Respir J 2007; 16: 378-383.

36 Singh SJ, Jones PW, Evans R, Morgan MD. Minimum clinically important improvement for the incremental shuttle walking test. Thorax 2008; 63: 775-777.

37 Hogg L, Garrod R, Thornton H, McDonnell L, Bellas H, White P. Effectiveness, attendance, and completion of an integrated, system-wide pulmonary rehabilitation service for COPD: prospective observational study. COPD 2012; 9: 546-554.

38 Waterhouse JC, Walters SJ, Oluboyede Y, Lawson RA. A randomised $2 \times 2$ trial of community versus hospital pulmonary rehabilitation, followed by telephone or conventional follow-up. Health Technol Assess 2010; 14: i-v, vii-xi, 1-140.

39 Cramm JM, Nieboer AP. The relationship between self-management abilities, quality of chronic care delivery, and wellbeing among patients with chronic obstructive pulmonary disease in The Netherlands. Int J Chron Obstruct Pulmon Dis 2013; 8: 209-214.

40 Walters J, Cameron-Tucker H, Wills K, Schüz N, Scott J, Robinson A et al. Effects of telephone health mentoring in community-recruited chronic obstructive pulmonary disease on self-management capacity, quality of life and psychological morbidity: a randomised controlled trial. BMJ Open 2013; 3: e003097.

41 Hynninen MJ, Pallesen S, Nordhus IH. Factors affecting health status in COPD patients with co-morbid anxiety or depression. Int J Chron Obstruct Pulmon Dis 2007: 2: 323-328.

42 Kapella MC, Herdegen JJ, Perlis ML, Shaver JL, Larson JL, Law JA et al. Cognitive behavioral therapy for insomnia comorbid with COPD is feasible with preliminary evidence of positive sleep and fatigue effects. Int $J$ Chron Obstruct Pulmon Dis 2011; 6: 625-635.

(i) $\Theta$ This work is licensed under a Creative Commons AttributionBY NC ND NonCommercial-NoDerivatives 4.0 International License. The images or other third party material in this article are included in the article's Creative Commons license, unless indicated otherwise in the credit line; if the material is not included under the Creative Commons license, users will need to obtain permission from the license holder to reproduce the material. To view a copy of this license, visit http:// creativecommons.org/licenses/by-nc-nd/4.0/ 